\title{
The Effectiveness of Rational Emotive Behavior Therapy to Decrease Aggressive Behavior in a Child with Alopecia
}

\section{Aryani Rahmah Utami ${ }^{\mathrm{a}}$ and Sri Redatin Retno Pudjiati ${ }^{\mathrm{b}}{ }^{*}$}

${ }^{a}$ Faculty of Psychology, Universitas Indonesia, Depok, Indonesia; ${ }^{b}$ Department of Developmental Psychology, Faculty of Psychology, Universitas Indonesia, Depok, Indonesia

*Corresponding author:

Sri Redatin Retno Pudjiati

Department of Developmental Psychology, Faculty of Psychology, Universitas Indonesia Jl. Lkr. Kampus Raya, Depok, Jawa Barat Indonesia, 16424

Tel.: +62 217270004

Email address: retno-pj@ui.ac.id 


\title{
The Effectiveness of Rational Emotive Behavior Therapy to Decrease Aggressive Behavior in a Child with Alopecia
}

\begin{abstract}
Anger often serves as a defense mechanism when handling conflict. It can also occur as part of the pathology of physical illness, and someone who has not been able to accept disfiguring symptoms such as alopecia may exhibit aggressive behavior. For the current research subject, alopecia led to bullying and mocking by those around him. The continual mistreatment led to anxiety for the research subject. He often thought negatively towards people who approached him and believed that they were judging him negatively. For example, when someone asked about the hat he was wearing, the participant immediately suspected that the person was mocking his baldness. The anger that the subject often felt was expressed eventually through aggressive behavior. Therefore, it became necessary to provide an intervention that the child could use to manage his anger and reduce his aggressive behavior. An intervention protocol using Rational Emotive Behavior Therapy was applied to the situation, and it was effective in training the research subject in anger management techniques and in decreasing aggressive behaviors.
\end{abstract}

Keyword: Aggressive Behavior; Anger Management; Rational Emotive Behavior Therapy; Alopecia in Children.

\section{Introduction}

Alopecia is a chronic dermatological disorder that can occur in children over two years old, making them lose some or all of their hair (Hunt \& McHale, 2005). Although this disorder is painless, alopecia patients will be disfigured. Their quite visible physical difference can make alopecia patients have bad feedback from their environment such as insults. More negative comments may lead to negative cognitions and emotions, such as anxiety, negative self-concept, distrust of appearing in public, and frequent bad thoughts about others. The long-term socio-emotional effects of alopecia may cause young patients to become disturbed and have difficulty with self-acceptance (Liakopoulou et al., 1997).

In middle childhood, medical conditions such as leukemia, liver cancer, and alopecia may lead the patient to experience a large amount of anger.

Sell, Tooby, and Cosmides (2009) stated that children who have not been able to accept themselves because of their illness require special assistance so that they do not get out of control with their emotions. When children get angry, they need modeling and assistance from their primary caregivers. When a lack of emotional regulation disrupts a child's family and social life, the child may need expert help to ensure that the situation does not develop into a more serious problem.

When a person feels angry, it indicates that the individual is in a dangerous situation, is threatened, or feeling hurt, and anger appears as a defense mechanism against the resultant problems (Smiley et al., 2016). A person who is feeling angry has physiological changes such as a flushed face, increased heart rate and blood pressure, and sweating. Their behavioral 
reactions are often characterized by resistance against (fight) or avoidance of (escape) the source of their anger (Blake \& Hamrin, 2007).

Even though anger is a natural emotion, its expression must be properly displayed as to not disturb or harm others (Smits \& Kuppens, 2005). When anger is expressed in the right way, such as writing in diaries, shouting in a place that does not disturb others, or hitting designated objects without hurting the self or others, anger becomes a positive thing. Aggressive behavior is defined as an action that aims to harm others in the form of physical actions such as hitting, kicking, or damaging items, and verbal actions such as loud crying, cursing, or shouting (Myers, 2012). This behavior does not occur in a vacuum. Research conducted by Eatough, Smith, and Shaw (2008) has shown that anger is one of the main causes of aggressive behavior. In addition, research conducted by Smits and Kuppens (2005) has shown that anger affects the aggressive behavior shown by children and adolescents.

When anger is expressed inappropriately, it can be detrimental. It can cause disrupted social relations (Smits \& Kuppens, 2005). Conversely, if the child expresses anger appropriately, their social relationship will remain good, and the child can show a positive attitude towards unpleasant situations (Smits \& Kuppens, 2005).

In this study, the participant was a 9-year-old boy with alopecia who had difficulty in managing his anger, which manifested in the form of aggressive behavior. The child had alopecia since the age of 2 years. At the age of five when he went to school, the child always wore a hat because he was ashamed of his baldness. Many of his friends questioned him about it and mocked him because he was the only child in class who did not have hair. Since he felt ashamed of his condition, the child never wanted to take off his hat outside his house. The child was considered to be at the average intelligence level with no academic problems. However, he was unable to manage his affect when he felt angry.

The anger seemed to have likely occurred because the participant had not been able to accept his baldness, so he was angry and acted out by hitting, cursing, and crying or passively avoiding others. Children with alopecia may also experience psychological problems, such as depression, withdrawal, aggressiveness, or delinquency (Liakopoulou, Aliferaki, \& Katideniou, 1997). In addition, many patients also have low self-esteem, low quality of life, and a bad body image (McGarvey, Baum, Pinkerton, et al., 2001).

The anger and frequent aggressive outbursts of the participant at school had a disruptive effect on his activities, especially in terms of friendship. In addition, he also began to avoid certain activities at school, such as Friday prayer in the school mosque and boy scout activities because he wanted to avoid encountering friends from other classes who might talk about his baldness. His teachers often punished the boy as his behavior also influenced the assessment of his attitudes.

Assessments administered by the current researchers showed that the participant's socioemotional situation led him to have irrational beliefs about himself and his status. It was also 
the cause of his aggressive actions. He thought that every time someone asked about the hat he was wearing, that person would soon start taunting him about his baldness. According to Ellis (2002), thoughts and feelings affect each other to produce behavior. The participant's automatic thoughts and beliefs made him behave aggressively towards people and situations that threatened his comfort.

To reduce the participant's aggressive behavior, he needed to be trained to manage his anger and to change his thinking through interventions based on cognitive therapy. Cognitive therapy focuses on helping people develop rational thinking about their problems (Flanagan, Allen, \& Henry, 2009). Through this intervention, the child was directed to identify problems and his thoughts about them to create a platform for rational thinking. In this way, the child could produce new behaviors that were more positive for encountering and solving problems.

The cognitive therapy chosen for the intervention combined cognitive change and emotional management to produce positive behaviors. This therapeutic intervention, called rational emotive behavior therapy (REBT), considers that the emotional problems experienced by individuals come from irrational beliefs, which then appear as inappropriate behavior such as aggressiveness (McCarthy \& Seid, 2010). In the current case, the participant needed to change his way of thinking to be more rational and learn how to manage his anger. This was found in REBT.REBT considers that humans are not disturbed by things outside themselves, but by their irrational beliefs about these things (Dryden, 2003). It is a treatment approach that prioritizes cognitive restructuring to change the irrational thinking that causes anxiety, depression, anger, guilt, and other psychological problems to develop (Ellis \& Bernard, 2006).

Treatment-focused research on the psychological effects of alopecia on patients is rarely found in the literature. Additionally, there has been no previous research of REBT applications for children experiencing emotional and psychological problems due to a medical condition.

\section{Method}

\section{Research Design Characteristics}

The research design used in this study was single-subject, or single-case design. This is a quasiexperimental research that uses pre-test and post-test procedures to determine the effects of a treatment or intervention.

\section{Research Instruments}

Measurements were carried out to monitor the anger and aggressive behavior of the participant using several tests. Anger was measured using the Beck Anger Inventory for Youth (BANI-Y) and a self-report anger thermometer worksheet. The aggressive behavior variable was measured using the Child Behavior Checklist (CBCL) and the Eyeberg Child Behavior Inventory (ECBI), and notes made by the participant's mother on his expressions of anger at home were used to determine changes in the frequency of aggressive behavior. The measurement tools were administered at pre-test, post-test, and follow-up sessions. 
BANI-Y is a measuring tool for children's thoughts about anger, hate, and unfair treatment. It is a self-report consisting of 20 items rated on a Likert scale. The results of the internal validity test conducted by the researchers stated that this instrument was valid with the item-total correlation score range from 0.203 to 0.858 . The reliability test results showed the BANI-Y instrument to be a very reliable instrument with a Cronbach's Alpha score of 0.866 .

The CBCL is a measuring tool used to look at potential problems in children from the aspects of internalization and externalization. It is a standardized questionnaire measuring the problematic behavior of children aged 4-18 years based on the assessments of parents or other caregivers who know the child's condition. The CBCL consists of 115 items grouped into three major behavioral problems categories, including internalizing behaviors (withdrawn, somatic complaints, anxious/depressed), externalizing behaviors (delinquent behavior, aggressive behavior), and problem groups (social problems, thought problems, attention problems). For the current study, the participant's mother assessed his behavior using the CBCL.

ECBI is a measuring tool used to find out the child's self-adjustment ability. This measuring instrument is done by a parent-report on 36 items included on a Likert scale. This instrument gives a result for an intensity score and a problem score. The intensity score displays the frequency of behavioral problems, and the problem score measures the extent to which parents consider the child's behavior as a problem. Validity and reliability testing were carried out on this instrument by Nida in 2017. The result showed that it was valid, with the item-total correlation score range from 0.264 to 0.726 , and reliability was shown with a Cronbach's Alpha score of 0.921 .

In addition, the participant was asked to identify the level of anger he felt using the anger thermometer to see changes in his levels of anger. His mother was also asked to record the expressions of anger made by the participant while at home.

\section{Participant Characteristics}

The participant was a 9-year-old primary school boy. He was taken by his mother for an examination to address his anger issues and aggressive actions at school and at home. The results of the examination showed that the participant had an average level of intelligence (full IQ: 99, WISC-R scale). He always wore a hat to cover his baldness, which made his friends ridicule him at school. Being exposed to these conditions, the participant grew into an anxious individual, especially when he was in a new place. He often thought negatively about people who approached him, and he believed that they were focused on and thought negatively about his baldness. When someone asked about the hat that he was wearing, the participant immediately suspected that the person wanted to mock him for being bald-headed.

\section{Research Procedure}

A study of the ethics of the research was conducted and fully approved by the Ethics Committee of the Faculty of Psychology at the University of Indonesia . After obtaining approval to conduct the study, the researchers conducted a role play of the implementation of REBT to determine the ability of the researchers to provide interventions and to learn to convey sentences that could 
be understood by children related to the REBT intervention process. After getting an evaluation of the results of the role play, the researchers fixed the module and began to administer the intervention for the participant.

\section{Program of Anger Management based on the REBT Principles}

The intervention phase consisted of ten intervention sessions. In these ten sessions, the child gained knowledge and training on the ability to manage anger and express it appropriately using REBT principles. The intervention was carried out two to three times a week

The number of intervention sessions conducted in this research was in accordance with the program plan of ten meetings. The schedule and execution time of the sessions were adjusted to fit the mother and the child's schedules. Sessions 2, 3, and 4 and sessions 5, 6, and 7 were combined into two sessions because the session discussions were of an interrelated topic. This merger also caused the researchers to repeat materials over again. Despite the merger of three sessions in one day, the material was not burdensome for the child. In addition, the sessions were still conducted at a two-hour-maximum. As a result, it took 5 days to complete sessions 19. The 10th session happened after a one month gap for the child to practice the principles of the intervention with real-world stimuli. The researchers conducted the follow-up session one month after the 10th session. Overall, this research was carried out for three months from February to May 2018, and then from June to July 2018, and one day in August 2018 for the follow-up session.

The REBT program for children is designed in a very concrete way for the participant. Not only are verbal discussions used, but visual assistance is also given to clarify the conversation about rational and irrational thinking. Mind mapping techniques are often used. Media enabled the child to understand the flow of thoughts easily.

The flow of the intervention process was started by giving psychoeducation to the mother and the participant regarding the concept of REBT in dealing with anger and aggressiveness. Then, there was a discussion about the feelings and behaviors [assessing emotional and behavioral consequences (C)] of the participant. It helped what he felt and did become more concrete for the participant. In addition, the participant was asked to identify events [assess activating event (A)] that might make him feel angry and behave aggressively. The next step was finding the beliefs that he had been using in interpreting the events that he experienced [assessing belief (B)]. After that, a dispute (D) technique was done to form a new rational belief.

In this study, the participant suffered from alopecia, a risk factor for him to be bullied. This situation was difficult to avoid. Therefore, the researchers were very concerned about the welfare of the participant, and they gave him reinforcement in the form of praise for making positive changes. Motivational Interviewing techniques were used when the participant was unable to make positive changes. The contents of motivational counseling stated by Beck (2012) are:

- Develop a reasonable goal and a reasonable plan. 
- Make a list of reasons for the importance of reaching the target and read the list every morning and at any time when you feel you have not met the target.

- Try to praise yourself when you feel you have reached the target as a form of selfappreciation.

- Be responsible for the plans that have been made.

- When a thought that makes you feel you cannot achieve the target emerges, deflect the thought and force yourself to do things as planned to reach the target.

- Identify the difficulties you face and look for problem-solving solutions.

- Understand that feelings of despair, disappointment, or deprivation will be felt in the process of reaching the target and that it is natural.

- Determine the gift you plan to get for yourself when you have reached the planned targets.

- Focus on the experience that you are going through.

- When the child is no longer behaving as planned, the child must start over.

\section{Child Outcome Characteristics.}

Indicators of successful implementation were stated as follows:

1. Changes in the mindset to become more rational and positive, such as:

- Not thinking that everyone who asks about his hat has the intention to mock him.

- Not feeling that everyone knew about his condition; thus, it was important for him to explain the use of hats.

2. Decreasing level of anger seen from the decreasing anger thermometer and

BANI- Y scores.

- No longer feels angry when someone asks about his hat.

- Behavioral changes in expressing anger. Becoming more assertive by expressing his discomfort when someone mocks his baldness and becoming able to answer questions related to his hats.

3. A decrease of the frequency of aggressive behavior seen from the mother's notes on his anger expression. A decrease in aggressive behavior intensity and problems as measured by the ECBI. A decrease in the level of aggressive behavior into a borderline or normal category as measured by the CBCL in the aggressive behavior area.

\section{Results}

\section{Implementation of the Research.}

Before the intervention was carried out, the researchers established a good relationship with the participant. It took one month until the participant trusted the researchers and was able to talk openly about his condition with them without being accompanied by his mother. This was difficult because of the bad experiences he had with friends that he lost and who let go of him after they were told about his condition.

\section{Effects by the Child's Outcome Measures.}

The intervention program consisted of the pre-intervention stage with a pre-test, the intervention stage with a post-test, and the follow-up stage. The pre-intervention stage was an assessment 
stage, carried out before the actual intervention with the aim of getting the initial data on the main problems. The intervention was carried out by applying REBT principles to anger management. After the intervention sessions were complete, the researchers conducted a posttest. This post-test was an evaluation carried out to determine the success of the intervention. The test was implemented after the 9th session. Finally, the follow-up session was conducted to assess the child's development after the intervention was completed. It was scheduled one month after the post-test session.

At each session, an interview was held with the child to assess his understanding of events; the anger thermometer and the BANI-Y were filled out by the child, and the CBCL, the ECBI, and the notes kept by the participant's mother on his expressions of anger at home.

A comparison of the participant's thinking processes over the course of the study was obtained through interviews with the child,--based on the results of assessments, and after the implementation of the intervention according to the REBT principles.

Table I. Results of Thinking Process

\begin{tabular}{|c|c|c|}
\hline \multirow{2}{*}{ Activities } & \multicolumn{2}{|r|}{ Results } \\
\hline & Pre-test & Follow up \\
\hline $\begin{array}{l}\text { The child's } \\
\text { understanding about } \\
\text { the consequences of } \\
\text { feelings and actions } \\
\text { (C) }\end{array}$ & $\begin{array}{l}\text { The child felt very angry and } \\
\text { acted aggressively in the form } \\
\text { of hitting, crying, and avoiding. }\end{array}$ & $\begin{array}{l}\text { Anger began to diminish and the actions } \\
\text { led to more assertiveness by answering } \\
\text { questions and not responding with } \\
\text { aggressive actions. }\end{array}$ \\
\hline $\begin{array}{l}\text { The child's } \\
\text { understanding about } \\
\text { the causes of anger } \\
\text { and aggressive } \\
\text { behavior (B-C) }\end{array}$ & $\begin{array}{l}\text { The anger he felt was difficult } \\
\text { to control until he acted out } \\
\text { with aggressive behavior such } \\
\text { as hitting. The child did not } \\
\text { know the cause of the anger he } \\
\text { had and did not know how to } \\
\text { control his anger. }\end{array}$ & $\begin{array}{l}\text { The child knew that the emergence of } \\
\text { feelings and actions came about because } \\
\text { of his interpretation of events (belief). } \\
\text { After he knew the cause and had } \\
\text { developed a more rational belief about it, } \\
\text { the child's anger became more } \\
\text { manageable and his aggressive behavior } \\
\text { decreased. }\end{array}$ \\
\hline $\begin{array}{l}\text { The child's } \\
\text { understanding about } \\
\text { the events he has } \\
\text { experienced (belief) } \\
\text { (B) }\end{array}$ & $\begin{array}{l}\text { His mind tended to be } \\
\text { irrational }\end{array}$ & His mind was more rational \\
\hline
\end{tabular}

From the comparison of the results in Table I, it can be seen that there were changes in the child's thinking processes. These changes led to positive development. The child also cooperated in applying the intervention to his daily life. The anger thermometer was a worksheet containing an assessment by the child of how angry he felt when a trigger for his anger arose. The researchers asked the participant about things that triggered his anger then asked him to identify the intensity or strength of anger that he felt on five scales. 


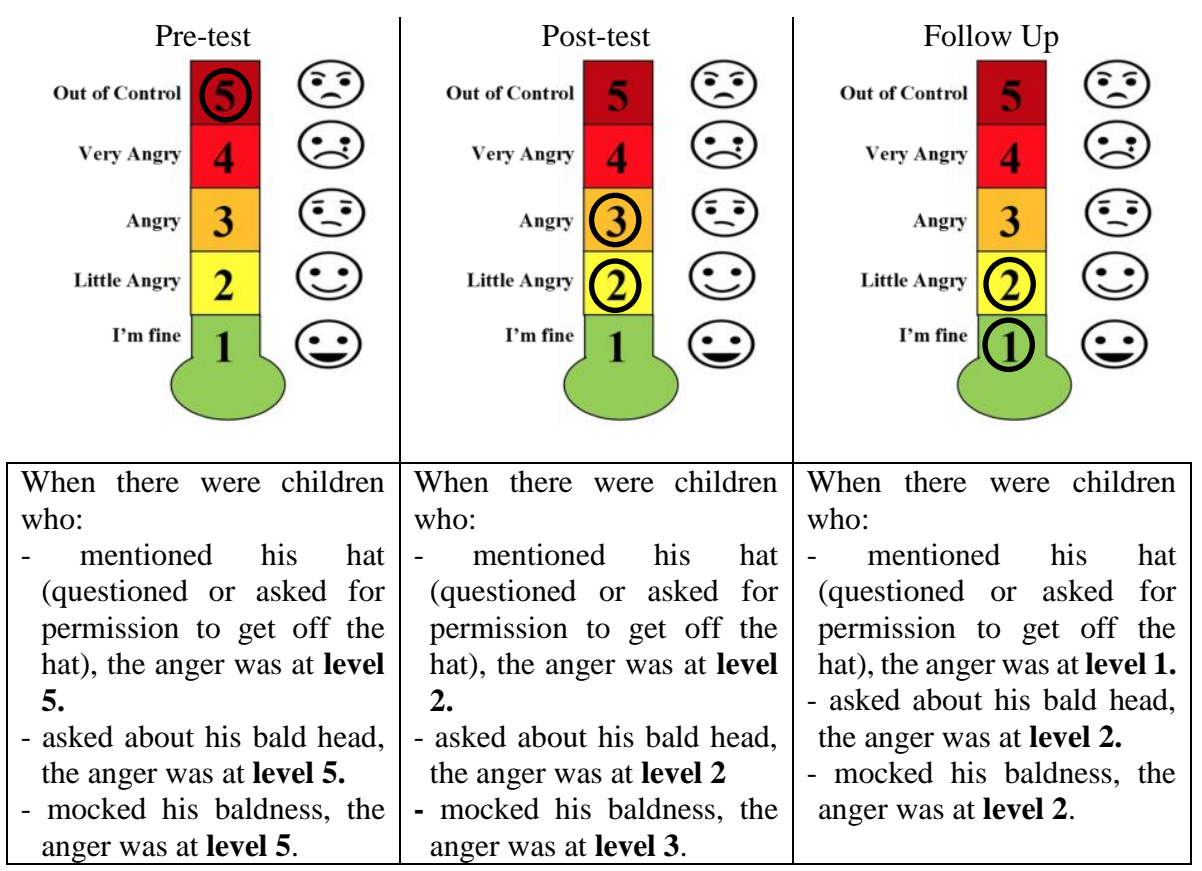

Fig. 1. Results of the Anger Thermometer in the Pre-Test, the Post-Test, and the Follow Up

Comparison of the anger thermometer results in Figure 1 shows that there is a decreased intensity of anger. The pre-test results showed the participant to be at a very high level of anger (score 5). The scores stated that when facing a situation that triggered anger, the child had no control over his behavior and could not think clearly. In the post-test, the scores were at an angry level (score 3) and a slightly angry level (score 2). These scores declared that the child could begin to sort out the triggers of his anger. Similarly, at the follow-up session, the intensity of his anger decreased depending on the trigger. This decreased intensity showed that he could begin to regulate his anger and did not generalize based on single incidents.

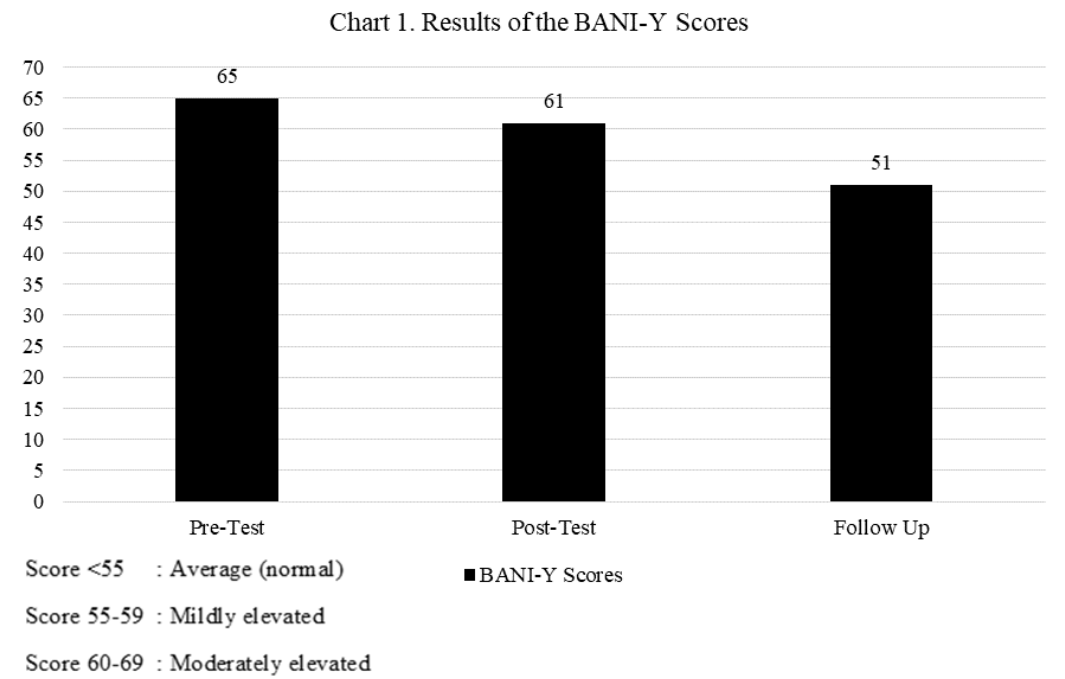

The results of the BANI-Y score comparison in Chart 1 show that after the intervention program was given, the participant showed changes in the assessment of himself with respect to his anger. Both the pre-test and post-test scores remained at the same level, which was quite 
high for someone at the participant's age level. Nevertheless, the scores did decrease by the follow-up session to a normal level.

Chart 2. Results of CBCL scores

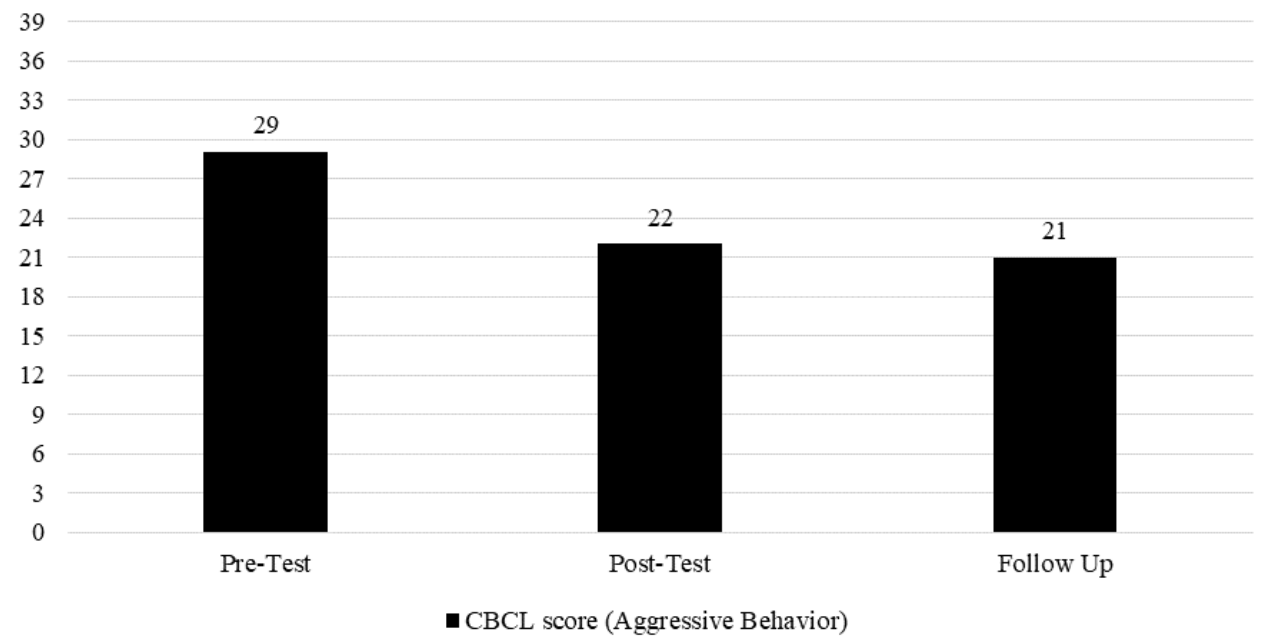

Fig. 1. Score 0-18 : normal

Fig. 2. Score 19-22 : borderline clinical range

Fig. 3. Score 23-40 : clinical range

The results of the CBCL comparison in Chart 2 show that after the intervention program was implemented, the child had a decrease in behavior problems. Before the intervention was done, the mother felt that the aggressive behavior was at the clinical threshold (score 29), meaning that However, after the intervention, at the post-test, and the follow-up session, the mother assessed the participant's aggressive behavior to be still on the borderline. This may have indicated that the mother had overly high expectations for her child's behavior because the aggressive behavior caused by the anger over the alopecia condition had diminished.

Of the 36 items in the ECBI, there were only 14 items that the mother considered problematic. Here is a comparison of the scores of the 14 items.

Table II. The ECBI Score Results

\begin{tabular}{lllll}
\hline \multirow{2}{*}{ No. } & \multirow{2}{*}{ Behavior } & \multicolumn{2}{l}{ Scores } & \\
\cline { 3 - 5 } & & Pre-test & Post-test & Follow-up \\
\hline 1 & Refuses to do chores when asked & 5 & 5 & 4 \\
\hline 2 & Acts defiant when told to do something & 5 & 5 & 4 \\
\hline 3 & Gets angry when doesn't get own way & 7 & 5 & 4 \\
\hline 4 & Has temper tantrum & 7 & 5 & 4 \\
\hline 5 & Cries easily & 7 & 7 & 7 \\
\hline 6 & Yells or Screams & 7 & 5 & 4 \\
\hline 7 & Teases or Provokes other children & 6 & 4 & 3 \\
\hline 8 & Verbally fights with brothers and sisters & 7 & 7 & 7 \\
\hline 9 & Physically fights with friends & 5 & 4 & 4 \\
\hline 10 & Physically fights with brothers and sisters & 5 & 5 & 5 \\
\hline 11 & Has difficulty entertaining himself alone & 6 & 5 & 4 \\
\hline
\end{tabular}




\begin{tabular}{lllll}
\hline 12 & Sasses adults & 4 & $\begin{array}{l}\text { No longer } \\
\text { a matter }\end{array}$ & $\begin{array}{l}\text { No longer } \\
\text { a matter }\end{array}$ \\
\hline 13 & Lies & 4 & $\begin{array}{l}\text { No longer } \\
\text { a matter }\end{array}$ & $\begin{array}{l}\text { No longer } \\
\text { a matter }\end{array}$ \\
\hline 14 & Verbally fight with friends & 4 & 4 & 4 \\
\hline Total scores of 36 items $=$ & 140 & 69 & 65 \\
\hline
\end{tabular}

The ECBI results in Table II show that there was no change in the problem scale score, which was at the lower clinical limit (normal score $=14$ ). Unlike the case with the intensity scale, there is a decrease in the scores from the pre-test (score $=140$ ) to the post-test the scores as it continued to decline until in the clinical range for normal (score $=69-65$ ). Scores on the problem scale showed that each problem the child had was quite high in severity at the time before the intervention was given. After the intervention was done, the follow-up session showed that the problem categories were within normal limits.

An anger expression comparison was obtained through the notes on expressions of anger compiled by the participant's mother. Table III gives a comparison of the child's pre-test and post-test behavior and expressions of anger.

Table 3. Results of Expressions of Anger

\begin{tabular}{llll}
\hline \multirow{2}{*}{ No. } & \multirow{2}{*}{ Cause Category } & \multicolumn{3}{l}{ Comparison of Angry Expressions } & Follow-Up \\
\cline { 3 - 4 } & & Pre-test & Post-test \\
\hline 1 & Someone mentioned his & Cried & Did not cry \\
hat (questioning, asking & Tried to avoid that person. & Did not avoid. \\
for permission to open hat) & $\begin{array}{l}\text { Did not answer the question } \\
\text { asked. }\end{array}$ & Answered the questions being asked. \\
& & Cried & Did not cry \\
\hline 2 & Someone mocked his bald & Hit & Did not hit \\
& head & Cursed & Did not curse \\
& & Avoided that person & Did not verbally convey his feelings \\
& & Did not verbally convey his & Remained quiet and tried to ignore his \\
& feelings & friend's ridicule. \\
\hline
\end{tabular}

The results in Table 3 show that there were behavioral changes in the child's expression of anger. The behavioral response after the intervention was assessed as more appropriate to the situation that triggered anger than it had been before the intervention. It was also considered more positive and assertive.

From the results of the post-test, it was found that the participant had not been able to express his feelings about when his friends mocked him. Therefore, in addition to structuring the intervention in accordance with the REBT principles, the researchers also provided motivational counseling to the participant after the post-test to discuss the importance of voicing his feelings. The child was encouraged to be firm towards things that could disturb him, and he promised to if someone disturbed him again. The researchers also reminded him to use phrases such as "I don't like being ridiculed!" or "Don't be like that!" to counter 
problematic thoughts and responses. However, at the follow-up session, the child still found it very difficult to express his feelings.

\section{Discussion}

This study found that an anger management intervention based on the REBT principles could reduce aggressive responses from a child when angry. This success can be seen from the changes in the participant's expressions of anger before and after the intervention was given. Before the intervention, the child expressed his anger in aggressive ways, such as hitting. After the intervention, he was more able to control his anger and not display aggressive behavior. When someone mocked his baldness, he no longer beat, cursed, and cried. There was no more explosive anger that was difficult to control. Instead, the participant would ignore the children who mocked him. In addition, the participant revealed that he felt calmer by the post-interview. From the mother's viewpoint, the child's emotional responses became much better after getting the intervention. When there was a trigger, the mother reported that the child was easier to calm and he was not dragged down in sadness and anger as he had at other times.

This success is also supported by Flanagan, Allen, and Henry's (2009) study, which found that REBT is effective in training children to manage their anger. The cognitive component is very instrumental in helping children with developing strategies for anger management. The cognitive processes underscored in the REBT encourage participants to accept their deficiencies, understand their behavioral errors, and find and overcome obstacles. When a child begins to understand the difference between the reality of situations and mistaken interpretations of situations, the child will come to an understanding that the event is not as problematic as it initially seemed. Thus, the child is then able to develop alternate responses that are more effective (Flanagan, Allen, and Henry, 2009). The intervention helps a child develop strategies to understand mistaken notions and improve the ability to manage anger.

REBT helps individuals make changes such as letting go of irrational beliefs and adopting a clear and insightful approach to relating to the world. When people have the experience of changing their philosophical framework, it can be expected that changes in emotions and behavior will follow (Dryden and Branch, 2008). When the participant was able to shape his thoughts into being more rational, he was able to make the behavioral and emotional changes he needed to get on track. By changing his mind and realizing that not everyone was seeking to mock him, the participant began to experience easier control of his emotions, and his behavior became less aggressive.

Anger management is a large part of affect regulation. Using emotion regulation theory, this study enabled the participant to manage his anger and emotions based on cognitive change strategies. These strategies help people to reassess events and other stimuli from a less emotionally unstable point of view (Gross, 2007). Thus, the participant succeeded in managing his anger by changing the way he perceived events, and he became calmer in dealing with situations that previously left him feeling angry and out of control. 
Anger management that involves cognitive change is very dependent on the child's cognitive abilities (Gross, 2007). In participants who have at least an average level of intelligence, it is fairly easy to understand how and why a situation can cause anger and to reassess problematic experiences to focus on more positive approaches and interpretations. This approach greatly helps children learn to regulate their emotions effectively.

In this study, motivational counseling was also given to help the participant reach his target behavioral goals. Motivational interviewing techniques based on the Beck approach were used to get the participant to change deeply held beliefs because one disadvantage of REBT is that it does not work well with children's failure to change immediately. Since children often present difficulties in making changes, the researchers anticipated this problem by providing additional sessions to address therapeutic targets that were not being achieved (Ellis, 2002). Motivational counseling was provided in order for the participant to gain increased confidence (Beck, 2012). Although motivational counseling was used in this study, the participant was still unable to behave assertively when teased by his friends. Basically, he did have a good understanding of the importance of expressing his feelings, but in practice, he was just too afraid to try it. Therefore, this child would benefit from additional help with learning to appropriately express his feelings to others.

Out of the five instruments used to measure the changes in the variables, the scores from BANIY remained unchanged from the pre-test to the post-test. BANI-Y was administered to the participant to assess perceptions of abuse, emotional, and physical feelings related to anger and negative thoughts about others obtained through subjective experiences. Because of the problematic environment and the bad experiences that the participant often encountered, changing old perceptions into new ones was not easy, and it took a long time. This explains why the BANI-Y post-test results were still at the same level as the pre-test. However, the other scores initially decreased and kept decreasing to normal for the participant's age when measured at the follow-up session. This indicates that the participant successfully changed to have more positive perceptions.

The aggressive behavior score on the CBCL was still on the borderline at post-test and followup even though they had decreased. However, the results of CBCL were obtained based on the participant's mother's view of the aggressive behavior of children. The high score may have been attributable to overly high expectations on the part of the child's mother. Nonetheless, the participant still showed many positive changes in respect to decreasing aggressive behaviors and emotional regulation.

Furthermore, several factors encouraged the success of this anger management intervention using REBT principles. The harmonious relationship built between the researchers and the participant was one of them. Trust and warmth in relationships are seminal to the process of implementing REBT. According to Ellis and Bernard (2006), the first thing that must be created in an REBT intervention with children is a belief in their story of the situations they have experienced and the importance of their thoughts and feelings. In this research, the researchers succeeded in building trust with the participant. He, who was previously reluctant to tell stories 
and felt his mother must always accompany him, eventually was willing to speak his truth to the researchers without having to be accompanied by the mother.

Commitment from the participant and his mother in undergoing the intervention also helped with the success of this research intervention. Both the mother and son attended every session, although the mother had to reschedule the 10th and the follow-up sessions. As a result, a wellestablished relationship and commitment from the participant and his parent made him able to undergo the sessions with a happy feeling. Ellis and Bernard (2006) have stated that positive rapport and the trust of participants can increase motivation to complete therapeutic interventions, and this was one of the supporting factors in the successful implementation of this program.

In addition to commitment, the participant's motivation to follow through with the intervention and to make changes was another factor influencing the success of this research. Awareness of the nature of the problems he was experiencing made the participant eager to make changes. According to Ellis and Dryden (1997), motivation to change strongly supports the success of a therapy. From the beginning of the assessment, the child was aware of the negativity of his feelings, and it gave him a strong motivation to undergo the intervention.

The materials presented were not only in verbal form but also in visual in the form of mind maps. The media made it very easy for the child to understand the flow of thoughts. In conducting assessments and evaluations, the use of thermometer images was effective for the participant to understand the intensity of his anger. The images were helpful because they were concrete and in accordance with the stage of development of the participant at that time (I.e., the participant was at the concrete operations stage of development).

This research has the limitation, of needing motivational counseling appended after the posttest, limiting the researcher's ability to measure the consistency of the post-test results. In addition, the use of motivational counseling is a different approach from REBT, and it will influence the REBT principles. The study also had an absence of direct observation regarding the participant's application of what he learned in the intervention to a real-world situation. Since there is no oversight, it is possible that participants can do faking-good when researchers are unable to observe their behavioral changes directly.

The potential that caregivers may lack understanding of the REBT process is also a weakness of this study. The participant's mother was only given a basic psychoeducational outline of the process from the researchers regarding REBT principles in training anger management and reducing aggressive behavior. Because of her limited understanding of the intervention framework, the participant's mother still had difficulties with helping the participant deal productively with situations that caused anger, and therefore, her role in the mother process was less than optimal.

If caregivers are not consistent in their attitude and approach to anger and emotions. it makes it difficult for children to change their perceptions. (Ellis \& Dryden, 1997). Cooperation between 
parents and other caregivers is very necessary for the success of the REBT intervention program. If, for example, the father is not very involved in the process of the intervention and tends to be indifferent, leaving any problem-solving to the mother, then the mother may feel unsure about the child's ability to make positive changes. Thus, a lack of confidence on the part of parents and caregivers can have a strongly deleterious effect on the outcome of the intervention program (Ellis \& Dryden, 1997).

\section{Conclusion}

Based on the results of this study, it can be concluded that an anger management intervention that uses REBT principles is effective in reducing aggressive responses in angry children who are at the age of middle childhood. REBT is effective in helping to change a previously irrational mindset to a more rational, more effective mindset, resulting in decreased aggressive behavior.

\section{References}

Beck, J. S. (2012). 10 techniques to increase motivation and willpower. Retrived from https://www.huffingtonpost.com/judith-s-beck-phd/cognitive-behavior-therapy_b_1199790.html.

Blake, C. S., \& Hamrin, V. (2007). Current approaches to the assessment and management of anger and aggression in youth: A review. Journal of Child and Adolescent Psychiatric Nursing, 20, 209-221.

Dryden, W. (2003). Rational Emotive Behaviour Therapy: Theoretical developments. Sussex: Brunner-Routledge.

Dryden, W., \& Branch, R. (2008). The fundamentals of rational emotive behaviour therapy: A training handbook (2nd Edition). Sussex: John Wiley \& Sons Ltd.

Ellis, A. (2002). Overcoming resistance: A Rational Emotive Behavior Therapy integrated approach (2nd Edition). New York: Springer Publishing.

Ellis, A., \& Bernard, M. (2006). Rational Emotive Behavioral approach to childhood disorders: Theory, practice, and research. New York: Springer.

Eatough, V., Smith, J. A., \& Shaw, R. L. (2008). Women, anger and aggression: An interpretative phenomenological analysis. Journal of Interpersonal Violence, 23, 1767-1799.

Flanagan, R., Allen, K., \& Henry, D. J. (2009). The impact of anger management treatment and Rational Emotive Behavior Therapy in a public school setting on social skills, anger management, and depression. Journal of Rational-Emotive \& Cognitive-Behavior Therapy, 28, 87-99.

Hunt, N., \& McHale, S. (2005). The psychological impact of alopecia. BMJ, 331, 951-953.

Liakopoulou, M., Alifieraki, T., Katideniou, A., Kakourou, T., Tselalidou, E., \& Tsiantisis, J. (1997) Children with alopecia areata: Psychiatric symptomatology and life events. Journal of the American Academy of Child and Adolescent Psychiatry, 36, 678-684.

McCarthy, Megan, \& Seid, Erika L. (2010). Instructor's manual for REBT for anger management with Janet Wolfe, PhD. Psychotherapy.net

McGarvey, E. L., Baum, L. D., Pinkerton, R. C., \& Rogers, L. M. (2001). Psychological sequelae and alopecia among women with cancer. Cancer Practice, 9, 283-288.

Myers, D. G. (2012). Psikologi Sosial Jilid 2. Jakarta: Salemba Humanika.

Pillay, S. (2016). Greater self-acceptance improves emotional well being. Harvard health Blog Publishing. Retrieved from https://www.health.harvard.edu/blog/greater-self-acceptance-improves-emotional-well201605169546

Sell, A., Tooby, J., \& Cosmides, L. (2009). Formidability and the logic of human anger. Proceedings of the National Academy of Sciences, 106, 15073-15078.

Smilley, P. A., Buttitta, K. V., Chung, S. Y., Coffey, J. K., Wang, B. A., \& Borelli, J. L. (2016). Anger in response to challenge: Children's emotion socialization predicts approach versus avoidance. Motivation Emotion, 40, 923-935. 
Smits, D. J. M., \& Kuppens, P. (2005). The relations between anger, coping with anger, and aggression, and the BIS/BAS system. Personality and Individual Differences, 39, 783-793.

Spiegler, M. D., \& Guevremont, D. C. (2010). Contemporary behavior therapy, fifth edition. Belmont: Wadsworth.

Thastum, M., Ravn, K., Sommer, S., \& Trillingsgaard, A. (2009). Reliability, validity, and normative data for the Danish Beck Youth Inventories. Scandinavian Journal of Psychology, 50, 47-44. 